\section{LOS CONTRATOS POR ADHESIÓN: RETROSPECTIVA Y PROSPECTIVA DE LA DEBILIDAD CONTRACTUAL EN EL DERECHO ARGENTINO*}

\author{
ADHESION CONTRACTS: RETROSPECTIVE AND PROSPECTIVE \\ OF CONTRACTUAL WEAKNESS IN ARGENTINE'S LAW
}

\section{Julieta Belén Trivisonno}

"Así como la resistencia de un puente no se mide por la fuerza promedio de sus pilares sino por la del pilar más débil, y la resistencia total crece a medida que aumenta la de este último, la confianza y los recursos de una sociedad se miden en función de la seguridad, los recursos y la confianza de sus sectores más débiles y crecen junto a ellos...”. Zygmunt Bauman. Vida de Consumo.

\title{
RESUMEN
}

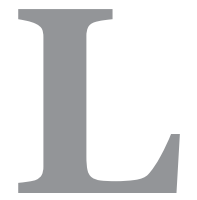
a propuesta del presente trabajo consiste en realizar una retrospectiva y prospectiva en torno a la tutela de la debilidad contractual, desde el punto de vista de la temática de los contratos por adhesión, analizando las reformas proyectadasy la legislación especial al respecto que conforman los antecedentes de la actual regulación de la figura. Asimismo, se analizan la influencia de la reforma constitucional de 1994 en dicha temática, la constitucionalización del Derecho Privado y la recodificación y unificación operada por el Código Civil y Comercial. Por último, se realiza un análisis preliminar de la tutela de la debilidad contractual desde una visión interdisciplinar.

Palabras clave: debilidad contractual, contratos por adhesión, derecho argentino

\section{ABSTRACT}

The proposal of this work consists of carrying out a retrospective and prospective about the protection of the contractual weakness, from the point of view of the subject of the contracts of adhesion, analyzing the projected reforms and the special legislation in that respect that conform the

\footnotetext{
* Trabajo realizado en el marco del Proyecto de Investigación 1DER173 "Retrospectiva y prospectiva de las instituciones del derecho contractual frente a la codificación y a la constitucionalización".
}

Julieta Belén Trivisonno jtrivisonno@gmail.com

Universidad Nacional de Rosario ARGENTINA

COMO CITAR ESTE ARTÍCULO Trivisonno, J. B. (2019). Los contratos por adhesión: retrospectiva y prospectiva de la debilidad contractual en el derecho argentino. Revista de la Facultad de Ciencias Económicas, 23 (2), 109 - 127. http://dx.doi.org/10.30972/rfce.2324022

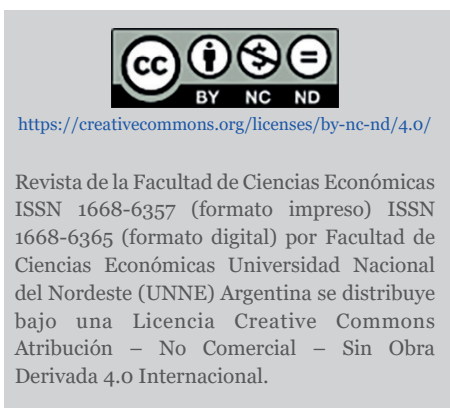


antecedents of the current regulation of the figure. Likewise, the influence of the 1994 constitutional reform on this subject, the constitutionalization of Private Law and the recoding and unification operated by the Civil and Commercial Code are analyzed. Finally, some considerations are made around the protection of contractual weakness from an interdisciplinary perspective.

Keywords: contractual weakness, adhesioncontracts, argentinelaw.

\section{INTRODUCCIÓN}

Los cambios operados durante el siglo XX en la realidad socio-económica fueron progresivamente relativizando el carácter individualista que poseía el Derecho Privado moderno, abriendo paso hacia una concepción más solidarista. En este marco, la ficción de la "igualdad ante la ley" -producto del racionalismo- fue cediendo ante el reconocimiento de las diferencias entre los sujetos y -por ende- de la necesidad de tutelar a aquellos que se encuentran en alguna situación de debilidad particular. Como se ha observado, se ha ido reemplazando la igualdad ante la ley por un "derecho desigual como instrumento de protección del sujeto débil y concreto”, verbigracia el consumidor” (De Lorenzo, 2005).

Este fenómeno fue estudiado en el marco del Derecho desde ópticas muy diversas. Entre ellas, destacamos los estudios de Duguit realizados en base a las conferencias que dictara el jurista en Buenos Aires, y que con posterioridad motivara la edición de su obra denominada "Las transformaciones generales del derecho privado después del Código de Napoleón”(Duguit, 1912); así como también las obras de los "socialistas jurídicos italianos" quienes llegaron a plantear la función social de los contratos (Cimbali, 1884; Panunzio, 1907).

En un clásico trabajo que data de 1935, Josserand observó que el Derecho se ha ido modificando y renovando para humanizarse; y en especial advirtió que “(...) la protección de los débiles es seguramente una de las preocupaciones más constantes del legislador contemporáneo; ella representa para él un objetivo de predilección, uno de los artículos de fe que se hallan inscriptos en el orden del día de la política mundial (...)”. Con suma agudeza para su época, supo visualizar el surgimiento de nuevas categorías de débiles jurídicos cuya característica común se halla en que la debilidad no es inherente a su propio ser, ni tampoco permanente y continua, sino que se presenta en función de una situación determinada, en el momento en que el sujeto se encuentra "agarrado en el engranaje de un orden económico o social determinado". Entre ellos cita al trabajador, a los industriales y comerciantes frente a grandes corporaciones y a "los clientes de grandes compañías" - a quienes hoy llamaríamos consumidores- que se ven 
obligados a adherir a las condiciones impuestas por éstas en el marco de un "contrato de adhesión”. Estos nuevos débiles son vistos como víctimas del orden social, económico, científico, dominados por fuerzas colectivas o mecánicas temibles; siendo tarea del derecho restablecer -dentro de lo posible- el equilibrio roto (Josserand, 1947).

En el Derecho Privado argentino, las exigencias de tutela de la debilidad y de mayor solidarismo comenzaron a manifestarse en la labor de la doctrina que luego se plasmó en la reforma al Código Civil de Vélez Sársfield que data de 1968. Tal reforma introdujo algunas modificaciones estratégicas destinadas a brindar una impronta más solidarista, entre ellas, la incorporación del instituto de la lesión, de la teoría de la imprevisión, el abuso de derecho y del principio de buena fe. ${ }^{1}$

En el ámbito del derecho contractual, la visión solidarista y la exigencia de atenerse a la igualdad real como principio rector, se traduce -en gran medida- en la necesidad de dar respuesta a las asimetrías que se presentan entre las partes y generan desequilibrios en los acuerdos. En ese marco, la propuesta del presente trabajo consiste en realizar una retrospectiva y prospectiva en torno a la tutela de la debilidad contractual, en especial en relación con la temática de los contratos por adhesión, analizando las reformas proyectadas y la legislación especial al respecto que conforman los antecedentes de regulación de la figura, la influencia de la reforma constitucional de 1994, la constitucionalización del Derecho Privado y la recodificación y unificación operada en el Código Civil y Comercial.

\section{LOS CONTRATOS CELEBRADOS POR ADHESIÓN: ANTECEDENTES EN EL DERECHO NACIONAL}

En el ámbito del Derecho argentino, el Código Civil de Vélez Sarsfield, abordó al contrato como una categoría conceptual única (art. 1137) basada en el principio de la autonomía de la voluntad, sin regular las diversas modalidades en la formación del consentimiento. Ello resulta lógico si tenemos en cuenta que tal cuerpo normativo data de 1869. Sin embargo, la cuestión no resultó del todo ajena a dicho Código ni al Código de Comercio. ${ }^{2}$

\footnotetext{
${ }^{1}$ Trabajo realizado en el marco del Proyecto de Investigación 1DER173 "Retrospectiva y prospectiva de las instituciones del derecho contractual frente a la codificación y a la constitucionalización".

${ }^{2}$ El Código Civil y el Código de Comercio -actualmente derogados por la Ley 26.994- contenían algunas normas limitativas de la autonomía de la voluntad en tanto declaraban inválidas determinadas cláusulas que hoy podrían tildarse de abusivas. Como ejemplos cabe citar: a) el art. 2232 del Código Civil según el cual en el marco del depósito necesario "El posadero no se exime de la responsabilidad que se le impone por las leyes de este Capítulo, por avisos que ponga anunciando que no responde de los efectos introducidos por los viajeros; y cualquier pacto que sobre la materia hiciese con ellos para limitar su responsabilidad, será de ningún valor"; y b) el art. 204 del Código de Comercio que disponía "Las empresas de ferrocarriles tienen la obligación de recibir toda la carga que se les entregue para el transporte hasta sus estaciones o las de otras líneas que empalmen con ellas. Los reglamentos o estipulaciones de las empresas que hubieren ofrecido sus servicios al público, excluyendo o limitando las obligaciones y responsabilidades impuestas por este Código serán nulas y sin ningún efecto".
} 
Con el correr del tiempo, ya desde la primera mitad del siglo XX, la estandarización, la predisposición negocial y la adhesión comenzaron a generar preocupación en la doctrina nacional, cuestionándose de este modo la capacidad del paradigma seguido por el codificador para captar las múltiples variantes derivadas de la realidad socio-económica (Hernández, 2007). La temática comenzó a verse reflejada en los diversos proyectos de reforma de la legislación civil y comercial, así como también en algunas leyes especiales verdaderamente precursoras.

En este sentido, el Proyecto de Reformas al Código Civil de 1936 incluyó dos normas que regulaban la oferta al público (arts. 805 y 806) concebidas como "breves reglas referentes a los contratos de adhesión"3. Por un lado, el artículo 805 que consideraba válidas aquellas ofertas al público en las que se estableciera que "no se dará curso a ninguna aceptación que modificare la propuesta" siempre que la oferta contuviese todas las cláusulas del contrato. En cambio, se considera nula la oferta que contenga tal cláusula pero no hubiese sido totalmente formulada por escrito. Por otro lado, el art. 806 disponía que en el caso de las ofertas al público, resultan de ningún valor las cláusulas ocultas o que se hicieren saber luego de la aceptación. ${ }^{4}$

En esta breve síntesis sobre los antecedentes relacionados con la regulación de la adhesión en el Derecho argentino, resulta importante aludir a algunas leyes especiales que abordaron la temática por medio de normas que limitaban el poder de configuración del contenido contractual. Así, en el ámbito inmobiliario comenzó a recurrirse a la estandarización para la comercialización de inmuebles -generalmente destinados a vivienda y a plazo-, cuestión que se prestaba a abuso por parte de los predisponentes, en tanto imponían cláusulas vejatorias que se traducían en un desequilibrio del contrato en perjuicio de los adquirentes. En reacción a estas circunstancias, se dictó la ley 14.005 de Venta de Inmuebles fraccionados en lotes y a plazo (B.O. 23/10/1950) establece la invalidez de aquellas cláusulas que facultaran al vendedor a resolver el contrato cuando se hubiese abonado el $25 \%$ del precio o se hubiesen introducido en el lote mejoras por un $50 \%$ de su valor. Con ello se evitaba el ejercicio irregular de la facultad de resolver el contrato por falta de pago de las cuotas, ya que resultaba habitual que el vendedor resolviera ante el incumplimiento del pago de las cuotas -aun habiéndose pagado un alto porcentaje del valor total del contratorecuperando la posesión del lote y apropiándose lo ya pagado por el comprador en concepto de cláusula penal. Teniendo en cuenta el conflicto abordado esta norma alcanzó gran aplicación práctica y trascendencia social (Santarelli, 2015). Otro antecedente en la materia lo hallamos en la Ley 19.724 de Prehorizontalidad (B.O. 13/07/1972) ${ }^{5}$ que -inspirada en el Código Civil italiano

\footnotetext{
3 “Reformas del Código civil. I. Antecedentes. II. Informe. III. Proyecto, GMO Kraft Ltd., Buenos Aires, 1936, t. I, p. 99.

${ }^{4}$ Proyecto de 1936. Art. 805 “En las ofertas al público, cuando ellas contuvieren todas las cláusulas del contrato, podrá establecerse que no se dará curso a ninguna aceptación que modificare la propuesta. Esta cláusula será nula cuando la oferta no hubiere sido totalmente formulada por escrito. La estipulación contenida en el presente artículo se juzgará implícita cuando se tratare de servicios públicos". Art. 806. "Para los casos del artículo precedente son de ningún valor las cláusulas ocultas, o que se hicieren saber después de la aceptación".

${ }^{5}$ Ley 19.724 de Prehorizontalidad fue recientemente derogada por el art. 3 de la Ley 26.994 (B.0. 8/10/14) que aprobó en su art. 1 el texto del nuevo Código Civil y Comercial de la Nación, actualmente vigente. Este Código reemplazó el sistema establecido por la ley derogada con los artículos 2070 y 2071.
} 
de 1942- creó un sistema de control de cláusulas abusivas en la comercialización de unidades en construcción a ser sometidas a propiedad horizontal. ${ }^{6}$

En materia de contrato de seguro, la Ley 17.418 (B.O. 6/9/67, art. 158) y la Ley 20.091 (B.O. 7/2/1973, art. 25), concibieron también dos mecanismos de control de cláusulas generales predispuestas: a. un control legal, estableciendo la inderogabilidad de algunas normas de la ley tuitivas del asegurado, así como también la posibilidad de modificar algunas disposiciones de la ley sólo en favor del asegurado; y b. un control administrativo a cargo de la Superintendencia de Seguros de la Nación con finalidad de prevenir la inclusión de cláusulas abusivas en los contratos (art. 25, ley 20.091/1973). En esta misma época, se produce la reforma del Código Civil de Vélez por medio de la Ley 17.711 (B.O. 26/04/1968), sin que se aprovechara la oportunidad para dar una regulación sistemática a esta modalidad contractual, no obstante lo cual se contribuyó a facilitar la labor de la jurisprudencia en el control de las cláusulas abusivas y en su interpretación al reconocer en forma expresa el principio de buena fe (art. 1198), el abuso del derecho (art. 1071) y la lesión (art. 954) (Esborraz, 2014).

Hacia la década del 80' los estudios sobre el tema se intensifican en la doctrina nacional, cuestión que se vio reflejada en las conclusiones de diversos eventos científicos de gran importancia. A título ejemplificativo cabe citar a las VIII Jornadas Nacionales de Derecho Civil (La Plata, 1981)7 cuya Comisión Nro. 3 se dedicó al estudio de los "Contratos con contenido predispuesto. Condiciones negociales generales”, recomendando la regulación de la temática en el marco del Código Civil y sugiriendo algunas pautas a tenerse en cuenta al momento de legislar en la materia. ${ }^{8}$

Siguiendo estas tendencias, el Proyecto de Unificación de la legislación civil y comercial de 1987 decide incorporar la modalidad de los contratos predispuestos, abordando la regulación de dos cuestiones en particular. Por un lado, en su art. 1157 el proyecto establece pautas para determinar el carácter abusivo de las cláusulas: "En los contratos con cláusulas predispuestas por una de las partes o que hagan referencia a condiciones generales, que la otra parte estuvo precisada a celebrar, se tendrán por no convenidas: 1) Las cláusulas que desnaturalicen las obligaciones, limiten la responsabilidad del predisponente por daños corporales, o la

\footnotetext{
${ }^{6}$ El art. 14 de la Ley 19.724 establecía que "Los contratos serán redactados en forma clara y fácilmente legibles. Las cláusulas que establezcan limitaciones de responsabilidad, facultades de rescindir o resolver el contrato sin previa comunicación o intimación, o suspender su ejecución o la de la obra, o sanciones a cargo del otro contratante, caducidades, limitaciones a las facultades de oponer excepciones, cláusulas compromisorias o de prórroga de la jurisdicción judicial, así como los supuestos previstos en los incisos f) y h) del artículo 13, sólo tendrán efecto si son expresamente aceptadas por el adquirente en cláusula especial, firmada por éste.

${ }^{7}$ Las Jornadas Nacionales de Derecho Civil constituyen en Argentina el evento más importante en la materia. Se celebran desde el año 1963 y reconocen como antecedente a los Congresos Nacionales de Derecho Civil realizados en la Universidad Nacional de Córdoba en el período 1927 a 1961. Las conclusiones de estos eventos científicos pueden ser consultadas en http://jndcbahiablanca2015.com ${ }^{8}$ Las Jornadas recomendaron: “A. En una reforma del Código Civil deben introducirse disposiciones que conformen un régimen destinado a regular los contratos con contenido predispuesto. Es conveniente que la ley los tenga en cuenta dedicándoles disposiciones específicas y haciéndose cargo de nuevas formas de violencia y nuevos supuestos de nulidad. B. Dicha regulación deberá declarar: a) la ineficacia de la cláusula que exonere o limite la responsabilidad por culpa grave o dolo del predisponente; la que disponga la inversión de la carga de la prueba; la que otorgue la facultad de resolver unilateralmente el contrato, o de suspender su ejecución, en ambos casos sin causa bastante, etc.; b) podrán anularse las cláusulas que, sin causa suficiente sancionen a cargo del otro contratante caducidades, limitaciones a la facultad de oponer excepciones, restricciones a la libertad de contratar con terceros, prórroga tácita o renovación del contrato, cláusulas compromisorias o de derogación de la competencia de la autoridad judicial".
} 
limiten por daños materiales sin una adecuada equivalencia económica. 2) Las cláusulas que importen renuncia o restricción a sus derechos, o amplíen derechos del predisponente que resulten de normas supletorias, salvo, en ambos casos, que conforme a las circunstancias haya conocido o usando la debida diligencia haya debido conocer estas cláusulas antes de concluir el contrato, y las haya aprobado expresamente y especialmente por escrito. La redacción deberá ser hecha en idioma nacional, y ser completa, clara y fácilmente legible”. En las notas explicativas los reformadores señalan que en el proyecto "Se incluyen disposiciones especiales para los contratos de contenido predispuesto por una de las partes, o referido a condiciones generales, el cual contrato la otra parte se vio obligada a celebrar". Como puede apreciarse, a la hora de la tutela de la parte débil en la negociación, no se hace hincapié en la predisposición negocial, sino más bien en el fenómeno de adhesión como factor que puede ser origen de los desequilibrios originados por las cláusulas vejatorias.

Por otro lado, se incorporan reglas hermenéuticas propias de este tipo de negocios en el art. 1197, inciso 3: "(...) Para la interpretación:... 3) En los contratos predispuestos: a) las cláusulas especiales prevalecen sobre las generales, aunque éstas no hayan sido canceladas. b) Las cláusulas incorporadas prevalecen sobre las preexistentes. c) Las cláusulas ambiguas serán interpretadas contra el predisponente. d) Si el no predisponente fuese una persona física, la interpretación se hará en sentido favorable a él. Se presumirá su liberación si es dudosa la existencia de una obligación a su cargo; cuando existan dudas sobre los alcances de su obligación se estará a la que le sea menos gravosa (...)". Como bien señalan los reformadores en las notas explicativas anexadas al proyecto, por un lado se despoja de efectos interpretativos a las prácticas en ocasiones llamadas vejatorias y al tratarse de personas físicas se acoge el principio favor debitoris.

El apoyo de la doctrina a dichas disposiciones no se hizo esperar. Las XII Jornadas Nacionales de Derecho Civil (Bariloche, 1989) -además de recomendar que se regule la predisposición negocial en el marco del Código- consideraron que los criterios que sentaba el este Proyecto sobre el tema resultaban en general adecuados ${ }^{9}$. La misma línea fue seguida por otros dos Proyectos de Reformas al Código Civil que datan de 1993 y que fueran elaborados por la Comisión Federal designada por la Cámara de Diputados de la Nación y por la Comisión creada por el Poder Ejecutivo Nacional.

Aunque ninguno de estos tres proyectos llegó a tener vigencia, oficiaron de antecedentes directos del régimen cláusulas abusivas consagrado la Ley 24.240 de Defensa del consumidor y del usuario (B.O. 15/10/1993) cuyo capítulo IX se titula "De Los Términos Abusivos y Cláusulas Ineficaces". El artículo 37 de dicha ley define a las cláusulas abusivas y las tilda de ineficaces señalando que "se tendrán por no convenidas" en el marco de cualquier contrato de consumo, no solamente en aquellos por adhesión a condiciones generales.

${ }^{9}$ XII Jornadas Nacionales de Derecho Civil (Bariloche, 1989), Comisión Nro. 8 "Impacto tecnológico y masificación social en el Derecho Privado". 
Con posterioridad, se elaboró el Proyecto de Código Civil para la República Argentina (en adelante Proyecto de 1998). Este proyecto trajo consigo una definición amplia de contrato (art. 889 inc. a) a la que sumó la distinción entre contratos discrecionales, contratos predispuestos, condiciones generales y contratos celebrados por adhesión ${ }^{10}$. Seguidamente, se agregan algunas normas relativas a la redacción de los contratos y las cláusulas predispuestas (art. 905), la asequibilidad de las cláusulas (art. 906), una sección completa dedicada a la regulación de las "Cláusulas abusivas en los contratos predispuestos" (arts. 968 a 970). Asimismo, se establecen normas propias de interpretación de los contratos predispuestos: la prevalencia de las cláusulas especiales sobre las generales (art. 1028, 2do párrafo) y la interpretación de las cláusulas predispuestas en el sentido más favorable a la parte no predisponente (art. 1033). El Proyecto de 1998 fue una de las principales fuentes utilizadas para la elaboración del CCyC, sobre todo en lo que respecta a la teoría general del contrato. Para advertir esta cuestión basta una rápida lectura de los Fundamentos ${ }^{11}$ que acompañaron el Anteproyecto de este cuerpo legal al ser presentado para su consideración ante el Poder Legislativo. No obstante ello, se optó por dejar de lado la metodología seguida en la definición de contrato por entender que la inclusión de varias nociones de contrato en un mismo artículo podría resultar confusa en la práctica y en la interpretación jurisprudencial.

\section{DERECHO CONSTITUCIONAL Y DERECHO PRIVADO: LA NUEVA RELACIÓN QUE PLANTEA LA REFORMA CONSTITUCIONAL DE 1994 Y LA TUTELA DE LA DEBILIDAD CONTRACTUAL}

La retrospectiva acerca de la tutela de la debilidad contractual puede hacerse también desde el punto de vista de la vinculación entre Constitución y Código Civil, en la relación entre el Derecho Constitucional y el Derecho Privado en diversas etapas: a) una primera etapa caracterizada por el "matrimonio difícil" (Saba, 2011) entre la Constitución de 1853/1860 (de raíz norteamericana) y el Código Civil de Vélez Sársfield, (propio del sistema jurídico continental) en el que predomina una concepción de contrato fuertemente basada en la autonomía de la voluntad y la igualdad formal entre las partes, b) una segunda etapa marcada por la llegada de la Constitución de 1949 que incorporó las ideas del constitucionalismo social, luego reemplazada por la Constitución de 1957 que preservó algunos de estos postulados y que de algún modo se reflejó en la adecuación del Código Civil por medio de la Ley 17.711 (1968). Tal como se señaló en el punto 1, la reforma infundió un espíritu solidarista en el sistema del Código Civil, atenuando la rigidez

\footnotetext{
${ }^{10}$ Proyecto de 1998. ARTíCULO 899.- Definiciones. Se denomina: a) Contrato, al acto jurídico mediante el cual dos (2) o más partes manifiestan su consentimiento para crear, regular, modificar, transferir o extinguir relaciones jurídicas patrimoniales. b) Contrato discrecional, a aquél cuyas estipulaciones han sido determinadas de común acuerdo por todas las partes. c) Contrato predispuesto, a aquél cuyas estipulaciones han sido determinadas unilateralmente por alguna de las partes; y cláusula predispuesta, a la cláusula del contrato en iguales circunstancias. d) Condiciones generales, a las cláusulas predispuestas por alguna de las partes, con alcance general y para ser utilizadas en futuros contratos particulares, sea que estén incluidas en el instrumento del contrato, o en otro separado. e) Contrato celebrado por adhesión, al contrato predispuesto en que la parte no predisponente ha estado precisada a declarar su aceptación.

${ }^{11}$ Los Fundamentos pueden ser consultados en: http://www.nuevocodigocivil.com/textos-oficiales-2/
} 
de la autonomía de la voluntad y del pacta sunt servanda por medio de la incorporación de institutos tales como la buena fe, el abuso del derecho y la lesión como vicio de los actos jurídicos.

Una tercera etapa se abre con la reforma constitucional de 1994 que introduce modificaciones de gran impacto en el ámbito del Derecho Privado. Entre ellas cabe destacar: a) el reordenamiento de la jerarquía de fuentes de nuestro sistema jurídico, b) el reconocimiento de rango constitucional a los tratados de derechos humanos enumerados en el art. 75 inc. 22 párrafo segundo ${ }^{12}$, c) la inserción en el texto constitucional de algunas normas tradicionalmente reservadas al ámbito del Derecho Privado y d) la incorporación de nuevos lineamientos en materia económico social.

En lo que respecta a los puntos b) y c), la doctrina civilista argentina, siguiendo la influencia extranjera, coincidió en llamar a este fenómeno "constitucionalización del Derecho Privado", en virtud de la recepción -en sede constitucional- de reglas relativas a la persona, a los derechos de la personalidad, a la familia, defensa del consumidor, etc., materias tradicionalmente reservadas al ámbito del Derecho Civil (Rivera, 1994; Lorenzetti, 1995; Nicolau, 1995; Sozzo, 2007).

En la cuestión que nos ocupa, se destaca la incorporación de principios generales del Derecho Privado a la Carta Magna, especialmente en el artículo 42, en el que adquieren estabilidad: a) el principio de buena fe contractual al señalarse que "Los consumidores y usuarios de bienes y servicios tienen derecho ...a una información adecuada y veraz; a la libertad de elección”, b) el principio de equidad, al establecerse que los consumidores tienen derecho a condiciones de "trato equitativo y digno”, c) el principio de orden público económico presente en el segundo párrafo de dicha disposición en el que se contempla: "Las autoridades proveerán a la protección de esos derechos, a la educación para el consumo, a la defensa de la competencia contra toda forma de distorsión de los mercados, al control de los monopolios naturales y legales, al de la calidad y eficiencia de los servicios públicos, y a la constitución de asociaciones de consumidores y de usuarios" (Nicolau, 1995).

El artículo 42, implica también un redimensionamiento del principio de igualdad ante la ley (art. 16), profundizando una idea de igualdad real (no formal), ya presente en los postulados del constitucionalismo social ${ }^{13}$, consolidando la necesidad de un "derecho desigual como instrumento de protección del sujeto débil y concreto", verbigracia el consumidor".

El principio de orden público económico presente en el art. 42 se vincula también a la incorporación de nuevos lineamientos económico sociales, que consolidan y propician la participación activa del Estado en la dirección del rumbo económico, profundizando el movimiento iniciado con anterioridad por el constitucionalismo social. Más allá de lo que el art. 42 implica

\footnotetext{
12 Respecto a la lectura sobre la Reforma de 1994 en lo relativo a la incorporación de los tratados de derechos humanos al art. 75 inc. 22 puede verse el análisis histórico realizado por: ROSATTI, Horacio, El Código Civil y Comercial desde el Derecho Constitucional, Rubinzal Culzoni, Santa Fe, 2016, p. 17 y ss. El autor señala que luego de la Segunda Guerra Mundial (1939-1945) los países occidentales "vencedores" en el conflicto, comienzan la construcción de un espacio jurídico internacional que comprende diversas declaraciones de derechos humanos, consideradas como expresión de una aspiración mínima común de los pueblos occidentales. Al incorporar al texto constitucional el art. 75 inc. 22, la Reforma de 1994 asume la "vertiente internacionalista" en materia de derechos humanos.

${ }^{13}$ Las ideas del constitucionalismo social, posteriores a la finalización de la Segunda Guerra Mundial, influyeron en la Constitución de 1949, posteriormente dejada sin efecto. No obstante, algunas de las ideas de dicho movimiento fueron incorporadas a la Carta Magna por la reforma de 1957.
} 
en materia de Defensa del Consumidor ${ }^{14}$, pueden deducirse de él dos de los principios nucleares del orden socio-económico argentino, por un lado el principio de economía de mercado, es decir una economía que sigue inmersa en el sistema capitalista con una clara subordinación del mercado a la Constitución; y por otro el principio de regulación estatal, que reviste al Estado de una función activa en la economía. Este último surge de las dos directivas contenidas en el párrafo segundo del art. 42: la facultad de las autoridades de tomar medidas para la defensa de la competencia y para evitar toda forma de distorsión de los mercados y el control de los monopolios, la eficiencia y calidad de los servicios públicos (Gil Domínguez, 1997). Se trata de obligaciones impuestas a las autoridades de todos los poderes del Estado que demandan acciones positivas por parte de ellas, acentuando de este modo la presencia y el rol del Estado en la moderación del mercado en defensa de la parte vulnerable de la relación de consumo (Bidart Campos, 1997).

Asimismo, pueden verse como lineamientos económicos otras disposiciones de la Carta Magna, entre ellas: a) el artículo 41 primer párrafo en tanto al consagrar el derecho a un medio ambiente sano, establece la obligación de las autoridades de proveer a la protección de tal derecho, al uso racional de los recursos naturales, a la preservación del patrimonio natural y cultural y de la diversidad biológica, la información y la educación ambientales. Tales obligaciones, que incumben a las autoridades de los tres poderes gubernamentales, conllevan la facultad de limitar en forma directa a las actividades comerciales e industriales (Bidart Campos, 1997); b) el principio de subsidiariedad, según el cual el Estado “(...) no debe poner obstáculos al impulso de la dinámica social espontánea y eficaz, sino articularla y hacerla coherente con el bien común. Debe deparar ayuda a la iniciativa privada eficiente, pero cuando esta resulta insuficiente o inepta, el Estado debe intervenir regulando el mercado o mediante prestaciones positivas (...)”; y c) el inc. 23 del artículo 75 que faculta al Congreso de la Nación a "Legislar y promover medidas de acción positiva tendientes a garantizar la igualdad real de oportunidades y de trato, y el pleno goce y ejercicio de los derechos reconocidos por esta Constitución y por los tratados internacionales vigentes sobre derechos humanos, en particular respecto de los niños, las mujeres, los ancianos y las personas con discapacidad”. Respecto de esta última norma se ha señalado que su horizonte es "amplio y elástico", y por ende, su contenido puede ser fácilmente traducido en términos económico-sociales, piénsese por ejemplo en los consumidores con vulnerabilidad agravada como categoría merecedora de una especial tutela. Asimismo, la importancia de esta norma radica también en su remisión a los tratados de derechos humanos, en virtud de lo cual se recuerda que el diseño socioeconómico de la Constitución Nacional también se compone de las normas contenidas en tales instrumentos

\footnotetext{
${ }^{14}$ La constitucionalización del derecho del consumidor contribuyó al fortalecimiento de esta rama incipiente -para esa entoncesen el derecho argentino, además de constituir en el marco del derecho comparado uno de los primeros antecedentes en la materia. Pocos meses antes de la reforma constitucional, fue sancionada la Ley 24.240 de Defensa de los Consumidores y Usuarios, siendo vetadas por el Poder Ejecutivo algunas de sus normas más significativas, v.gr. el art. 40 relativo a la responsabilidad por producto elaborado. La jerarquía constitucional de estos derechos exigió la adecuación del régimen infraconstitucional, arrojando como resultado la reincorporación paulatina de las normas vetadas al texto de la ley especial citada.
} 
internacionales, específicamente aquellos que poseen jerarquía constitucional de acuerdo a lo establecido por el art. 75 inc. 22 (Bidart Campos, 1997).

El brevísimo recorrido realizado da cuenta de la profunda dimensión del impacto de la Reforma de 1994 en el Derecho Privado argentino. En este sentido, y con gran visión, se sostuvo que tal reforma produjo un movimiento de renovación del Derecho argentino que "obliga a nuestros juristas a reflexionar, con visión interdisciplinaria, sobre la íntima y necesaria relación entre el Derecho Público y el Derecho Privado, despertando en ellos un saludable interés en analizar los aspectos constitucionales del Derecho Privado"(Nicolau, 1995). Así, la supremacía constitucional demanda la adecuación de los ordenamientos jurídicos de inferior jerarquía a los nuevos paradigmas adoptados por medio de la reforma de los Códigos y de las leyes especiales pertinentes.

En lo que respecta a la legislación civil y comercial, la adecuación se hizo esperar y las dificultades producidas, se fueron canalizando a través de la modulación de los principios generales del Derecho Privado de corte más bien solidarista, introducidos en el Código Civil de Vélez por la reforma de la Ley 17.711 (Nicolau, 1995). En este sentido han cumplido un rol central los estándares de la buena fe y el abuso del derecho.

Aún hoy nuestro ordenamiento jurídico se halla transitando tal proceso de adecuación, cuyo avance ha sido sumamente significativo en los últimos años, en particular con la entrada en vigencia del Código Civil y Comercial a partir del $1^{0}$ de agosto de 2015. Este nuevo cuerpo normativo reafirma la necesidad de una revinculación entre código y constitución, contribuyendo a diluir la tajante división entre Derecho Público y Derecho Privado.

En efecto, los codificadores señalaron en forma expresa que el Código recepta el fenómeno de la constitucionalización y "establece una comunidad de principios entre la Constitución, el derecho público y el derecho privado, ampliamente reclamada por la mayoría de la doctrina jurídica argentina. Esta decisión se ve claramente en casi todos los campos: la protección de la persona humana a través de los derechos fundamentales, los derechos de incidencia colectiva, la tutela del niño, de las personas con capacidades diferentes, de la mujer, de los consumidores, de los bienes ambientales y muchos otros aspectos...". ${ }^{5}$

\section{LOS CONTRATOS CELEBRADOS POR ADHESIÓN A CLÁUSULAS GENERALES PREDISPUESTAS EN EL CCYC}

Una de las modificaciones de mayor relevancia introducidas por el Código Civil y Comercial en materia contractual, se halla en la incorporación de la categoría de los contratos por adhesión a cláusulas generales predispuestas en el Capítulo 3 "Formación del Consenti-

\footnotetext{
${ }^{15}$ Pueden consultarse los Fundamentos del Anteproyecto de Código Civil y Comercial de la Nación, en http://www. nuevocodigocivil.com/wp-content/uploads/2015/02/5-Fundamentos-del-Proyecto.pdf
} 
miento" del Título II dedicado a los "Contratos en general” entre los artículos 984 y 989. El emplazamiento metodológico de esta temática se vincula al carácter de modalidad contractual que la adhesión posee, en tanto es entendida como un camino para arribar al consentimiento en el marco del fenómeno de masificación y estandarización de los contratos.

El artículo 984 del CCyC define al contrato por adhesión a condiciones generales de contratación como “(...) aquel mediante el cual uno de los contratantes adhiere a cláusulas generales predispuestas unilateralmente, por la otra parte o por un tercero, sin que el adherente haya participado en su redacción (...)”. A continuación de la definición, el CCyC establece algunas normas hermenéuticas y un régimen de control de inclusión y de contenido propios, ambos marcadamente tuitivos de la parte que es considerada débil; el adherente.

La nota que define a esta categoría contractual se encuentra en el modo en que se forma el consentimiento a través de la adhesión de una de las partes a las condiciones contractuales predispuestas por la otra, sin que exista para aquella la posibilidad de configurar el contenido del vínculo. En otras palabras, el CCyC considera merecedora de amparo la situación de quien carece de poder de negociación y adhiere a las cláusulas predispuestas por otro, y no refiere al fenómeno de la predisposición en abstracto. La terminología utilizada por el Código da cuenta de ello, en tanto se habla de "contrato por adhesión" y no de "contratos predispuestos", así como también la inclusión de esta temática en el ámbito de la formación del consentimiento.

Además, en este mismo sentido se manifiestan en forma expresa los Fundamentos que acompañaron la presentación del Anteproyecto del CCyC, elaborados por los juristas integrantes de la comisión redactora del Código. En ellos se explica que "El contrato se celebra por adhesión cuando las partes no negocian sus cláusulas, ya que una de ellas, fundada en su mayor poder de negociación, predispone el contenido y la otra adhiere. La predisposición, en cambio, es una técnica de redacción que nada dice sobre los efectos. El contenido predispuesto unilateralmente puede ser utilizado para celebrar un contrato paritario, o uno por adhesión o uno de consumo. La razón de ello es que hay muchos contratos en los que la predisposición de las cláusulas no es un indicio de la debilidad de una de las partes: esto puede ocurrir porque los contratantes disminuyen los costos de transacción aceptando un modelo de contrato predispuesto por una de ellas o por un tercero". En el fragmento transcripto se hace manifiesta la intención del legislador de brindar protección a la situación de debilidad en la que se encuentra una de las partes cuando el contrato se forma por adhesión a cláusulas generales, advirtiendo de este modo que la predisposición negocial no constituye en sí misma una práctica disvaliosa.

En el fragmento transcripto -además de esclarecerse el ámbito de tutela de la categoría de los contratos por adhesión- se hace manifiesta la intención del legislador de brindar protección a la situación de debilidad en la que se encuentra una de las partes en esta modalidad contractual. A su vez, para que un contrato pueda ser encuadrado en esta categoría, además de la ce- 
lebración por adhesión, es preciso que concurran otros dos requisitos que se desprenden del mencionado art. 984:

a. El carácter general de las cláusulas, que deben haber sido concebidas por el predisponente para un número indeterminado de negocios a celebrarse con una pluralidad de sujetos no determinados $a b$ initio. La Comisión redactora del CCyCN señala que en el ámbito contractual se entiende por cláusula general aquellas que “(...) son redactadas para una generalidad de sujetos en forma previa y no modificable mediante la negociación individual (...)”. Con ello, también quedarían excluidos de este ámbito aquellos contratos celebrados por adhesión cuyas cláusulas fueron unilateralmente predispuestas para un único y determinado contrato, pues en este caso el adherente cuenta con mayor posibilidad de sugerir alguna modificación al texto predispuesto; nos hallamos en el ámbito de la contratación individual motivo por el cual no se justificaría la aplicación de un régimen especial de tutela del consentimiento propio de los contratos estandarizados (Esborraz, 2014).

b. La predisposición unilateral de tales cláusulas, es decir, la elaboración de las mismas por una de las partes sin la más mínima intervención de la otra en la redacción, quedando en sus manos solamente la facultad de adherir o no a las mismas. Esta circunstancia aumenta el riesgo de que puedan presentarse cláusulas abusivas, justificando la existencia del régimen especial de interpretación y control de contenido y de incorporación de tales cláusulas. Por otra parte, cabe destacar que el artículo 984 del CCyC contempla la posibilidad de que las cláusulas hayan sido redactadas en forma unilateral por un tercero, distinto de los contratantes. Quedarían comprendidos en esta categoría aquellos supuestos en que las cláusulas sean redactadas por representantes o por un consultor legal, así como también el uso de formularios pre impresos o modelos de contratos, entre otros ejemplos. Se ha sostenido que también se encuentra alcanzado el supuesto de quien se encuentra obligado a utilizar un determinado esquema contractual debido a un contrato normativo unilateral en el cual es parte (Esborraz, 2014).

Siguiendo los lineamientos básicos de proyectos anteriores, se regulan los aspectos centrales vinculados a la tutela de la parte que adhiere a las condiciones contractuales impuestas por la otra, entre ellos, el control de inclusión (art. 985), las cláusulas particulares art. 986), la interpretación (art. 987) el control de contenido (art. 988 y 989).

Los cambios introducidos por el Código Civil y Comercial implican la materialización de una importante transformación en la noción de contrato en nuestro derecho. Desde la doctrina se ha considerado que se conforman nuevas categorías contractuales que producen el quiebre de una noción única de contrato, entendido como negocio jurídico celebrado entre dos partes que se encuentran en pie de igualdad y que por tanto, poseen similar poder para negociar el contenido contractual (Hernández, 2016). En otros términos, se ha dicho que se plasman tres géneros de contrato: la "regla general" identificada con los contratos discrecionales o paritarios, el contrato de consumo y a mitad de camino entre ambos, los contratos por adhesión 
(Esborraz, 2014). Desde otra perspectiva, se apunta que se trata de la incorporación de reglas expresas en relación con los contratos por adhesión como modalidad contractual, sin que se produzca un quiebre tipológico (Nicolau, 2016).

Los Fundamentos del Código Civil y Comercial explican la idea del fraccionamiento de la categoría del contrato, al señalar que "(...) El sistema queda ordenado entonces de la siguiente manera: a. Contratos discrecionales: en ellos hay plena autonomía privada. b. Contratos celebrados por adhesión: cuando se demuestra que hay una adhesión a cláusulas generales redactadas previamente por una de las partes, hay una tutela basada en la aplicación de este régimen. c. Contratos de consumo: cuando se prueba que hay un contrato de consumo, se aplica el Título III, sea o no celebrado por adhesión, ya que este último es un elemento no tipificante (...)". ${ }^{16}$

El encuadramiento de un negocio determinado en una u otra categoría contractual determinará importantes diferencias en lo que respecta al régimen aplicable. De acuerdo a las circunstancias, podremos hallarnos frente a un contrato paritario, regulado a partir del art. $957 \mathrm{y}$ tributario de los principios de autonomía y efecto vinculante (arts. 958 y 959); frente a un contrato por adhesión a condiciones generales cuyo régimen se dirige a neutralizar los efectos negativos de los abusos en que pueda incurrir el predisponente; o bien frente a un contrato de consumo, rico en normas tuitivas de quien se encuentra en una situación de debilidad estructural, con independencia de la modalidad utilizada para arribar al consentimiento (arts. 1092 a 1104 y Ley 24.240).

Sea cual fuera la postura que se siga, introducción al Código de las nuevas categorías de contrato implica dar respuesta a la exigencia de protección de la vulnerabilidad del contratante de acuerdo a las circunstancias en las que se produce la contratación. De este modo, se consolida una importante tendencia encaminada a imponer límites al poder de configuración unilateral del contenido contractual y al fenómeno de la adhesión, tanto desde los principios generales del Derecho Privado -tales como la buena fe y el abuso de derecho- como por medio de leyes especiales, en línea con un orden público de protección que intenta morigerar el principio de obligatoriedad de los contratos (Hernández, 2007).

\section{TUTELA INTERDISCIPLINARIA DE LA DEBILIDAD CONTRACTUAL: EL INSTITUTO DEL ABUSO DE DEPENDENCIA ECONÓMICA EN EL ÁMBITO DE LA DEFENSA DE LA COMPETENCIA Y LA LEALTAD COMERCIAL}

En una visión del derecho contractual en clave interdisciplinaria, es posible hallar algunas figuras propias del ámbito de la defensa de la competencia y la lealtad comercial que se encuentran fuertemente vinculadas a la tutela del contratante débil, específicamente de

${ }^{16}$ Los Fundamentos pueden ser consultados en: http://www.nuevocodigocivil.com/textos-oficiales-2/ 
la pequeña y mediana empresa. Desde una visión relacional del contrato, la categoría de la contratación por adhesión presenta algunas limitaciones, cuyo tratamiento puede abordarse y complementarse desde otras disciplinas diversas al derecho contractual.

En tal sentido, en la legislación comparada se ha desarrollado la figura del "abuso de situación de dependencia económica”. En el Derecho español, la Ley de Competencia Desleal Nro. 3/1991 establece en su art. 16 inc. 2 que "Se reputa desleal la explotación por parte de una empresa de la situación de dependencia económica en que puedan encontrarse sus empresas clientes o proveedores que no dispongan de alternativa equivalente para el ejercicio de su actividad. Esta situación se presumirá cuando un proveedor, además de los descuentos o condiciones habituales, deba conceder a su cliente de forma regular otras ventajas adicionales que no se conceden a compradores similares". La figura encuentra también recepción en Italia (art. 9 inc. 3 Ley 192 de 1998), Francia (Ordenanza 86-1243 del 1/12/1986, introduce en el Código de Comercio arts. 420-2 y 420-3) y Ecuador (Ley orgánica de regulación y control del poder de mercado).

La figura de la dependencia económica, fue desarrollada para socorrer a los contratantes de menor envergadura que se relacionan con las grandes empresas, los grandes oferentes del mercado observa; tutelando a aquellos que se encuentran en una situación tal que otorgan al dominante un amplio margen de discrecionalidad en las relaciones contractuales, lo que determina una continuidad dependiente que no encuentra alternativas suficientes fuera de la mentada relación. Se refiere a la relación de poder en términos relativos, considerando el vínculo contractual concreto en el que se imponen desventajas onerosas para el dependiente, quien se ve constreñido a aceptarlas en tanto no posee en el mercado otras alternativas satisfactorias para obtener el rendimiento de su inversión (Santarelli, 2018). Podría ser el caso, verbigracia, de los distribuidores, agentes, concesionarios en vinculación con los grandes productores o fabricantes (industria automotriz, industria láctea), el supuesto de la vinculación de los supermercados con los pequeños o medianos fabricantes o productores, la vinculación de las grandes acopiadoras con los micro, pequeños y medianos transportistas.

Cabe deslindar similitudes y diferencias entre abuso de posición dominante y abuso de dependencia económica. Por un lado, tienen en común -como puede advertirse en la denominación de las figuras- el elemento del abuso, que conduce a pensar en el mal uso de un cierto poder, motivo por el cual en la doctrina comparada se ha considerado que el abuso de dependencia económica puede incluirse como un matiz de la figura más abarcativa del abuso de posición dominante. Por otro lado, las figuras contemplan distintos supuestos de hecho que permiten diferenciarlas. Así, en términos muy simplificados, el abuso de posición dominante se refiere al mal uso del poder realizado por quien detenta una posición de dominio en el rubro en que se desempeña y por su parte, el abuso de dependencia económica tiene por fin socorrer a los contratantes de menor envergadura que se relacionan con los grandes oferentes del mercado. Se evidencia en el primero la incidencia macroeconómica del abuso en un sector del mercado, 
mientras que en el segundo la incidencia microeconómica del abuso considerada en cada caso concreto (Santarelli, 2018).

La cuestión no resulta extraña al Código Civil y Comercial, que en su título preliminar, evidenciando su vocación en la construcción de un verdadero sistema de Derecho Privado, sienta las bases legales para el desarrollo de esta tutela en tanto consagra los siguientes lineamientos generales: a) el principio general de buena fe (art. 9) y del abuso del derecho (art. 10), b) la disposición contenida en el art. 11 del Código Civil y Comercial, cuyo espíritu veda toda situación de abuso de posición dominante en el ámbito del mercado. Con ello se brinda un marco de principios y normas que le permiten al Estado orientar las prácticas negociales en la relación entre empresas de envergadura económica dispar, permitiendo corregir las distorsiones y desequilibrios que se generan en el mercado, respecto de los cuales otras herramientas derivadas del principio protectorio resultan insuficientes.

En el ámbito del derecho nacional, la figura del abuso de situación de dependencia económica fue introducida en el Decreto 274/19 sobre Lealtad Comercial. Luego de establecer una cláusula general en el artículo 9 que define al acto de competencia desleal, consagra los supuestos particulares en el artículo siguiente. Entre ellos se encuentra la figura del abuso de situación de dependencia económica (art. 10 inc. d), definida como un acto de competencia desleal consistente en "Explotar la situación de dependencia económica en que pueda encontrarse una empresa cliente o proveedora que no disponga de una alternativa equivalente para el ejercicio de su actividad en el mercado. Esta situación se presumirá cuando un proveedor, además de los descuentos o condiciones habituales, deba conceder a su cliente, de forma regular, otras ventajas adicionales que no se conceden a compradores similares".

La consagración de la norma resulta positiva en cuanto desarrolla otra faceta del principio protectorio en la relación entre empresas, diversa a la que se plasma en el marco de la contratación por adhesión, dentro del marco constitucional y del Código Civil y Comercial, a los cuales se hiciera referencia en el curso del presente trabajo. La figura expresa, además, el creciente interés del Derecho Privado en el concepto de situación jurídica, cuestión que se pone de manifiesto en nuestro Código Civil y Comercial en la consagración de la figura de la situación jurídica abusiva (art. 1120).

\section{CONCLUSIONES}

De acuerdo a lo analizado en el presente aporte, en el ámbito del derecho contractual, la visión solidarista del Derecho Privado y la exigencia de atenerse a la igualdad real como principio rector, se traduce -en gran medida- en la necesidad de dar respuesta a las asimetrías que se 
presentan entre las partes y generan desequilibrios en los acuerdos, dando vida a la categoría de contratos por adhesión.

Al realizar un análisis retrospectivo de esta categoría desde el punto de vista del Derecho Privado argentino, se ha advertido que la regulación de los contratos por adhesión posee antecedentes en los diversos proyectos de reforma ${ }^{17}$, entre los que se destaca el Proyecto de Unificación de la Legislación Civil y Comercial de 1987, cuyas elaboraciones fueron seguidas por los Proyectos de 1993 y constituyeron el antecedente del art. 37 de la Ley 24.240.

Asimismo, se presentan importantes antecedentes en algunas leyes especiales verdaderamente precursoras en la materia, tales como la ley 14.005, 19.724, entre otras. Por su parte, el Proyecto de 1998 avanza en la misma dirección -aunque con algunas diferencias metodológicas, sirviendo de base al actual Código Civil y Comercial.

En miras a una retrospectiva desde el punto de vista del Derecho Constitucional, cabe señalar que reforma de la Carta Magna llevada a cabo en 1994 introduce modificaciones de gran impacto en el ámbito del Derecho Privado, entre ellas el reconocimiento de rango constitucional a los tratados de derechos humanos enumerados en el art. 75 inc. 22 párrafo segundo, la inserción en el texto constitucional de algunas normas tradicionalmente reservadas al ámbito del Derecho Privado y la incorporación de nuevos lineamientos en materia económico social. El nuevo Código Civil y Comercial se propone adecuar el régimen infraconstitucional a las modificaciones introducidas por aquella reforma, cuestión que en materia contractual se traduce en la incorporación de la categoría de los contratos por adhesión y de consumo a modo de quiebre de la concepción única de contrato.

A su vez, en una visión del derecho contractual en clave interdisciplinaria, es posible hallar algunas figuras propias del ámbito de la defensa de la competencia y la lealtad comercial que se encuentran fuertemente vinculadas a la tutela del contratante débil, específicamente de la pequeña y mediana empresa. Entre ellas, destacamos el abuso de situación de dependencia económica, receptado recientemente en el Decreto 274/2019, cuya finalidad es la de socorrer a los contratantes de menor envergadura que se relacionan con los grandes oferentes del mercado, quienes al no tener una alternativa equivalente para seguir desarrollando su actividad, se ven obligados a aceptar condiciones contractuales desventajosas. La tutela de la debilidad contractual desde esta perspectiva complementa y enriquece el régimen previsto en el Código Civil y Comercial relativo al fenómeno de la adhesión.

\footnotetext{
${ }^{17}$ Durante el SXX se sucedieron en nuestro país una serie de proyectos de reforma a la legislación civil y comercial: a. Proyecto de 1926 (elaborado por Juan Antonio Bibiloni), b. Proyecto de 1936; c. Proyecto de 1954 (dirigido por Jorge Joaquín Llambías), d. Proyecto de Unificación de la Legislación Civil y Comercial (Cámara de Diputados de la Nación, año 1987), e. Proyecto de la Comisión Federal de la Cámara de Diputados de la Nación de 1993, f. Proyecto de la Comisión creada por decreto del Poder Ejecutivo Nacional 468/92, y g. Proyecto de 1998, preparado por la Comisión creada por decreto del Poder Ejecutivo Nacional 685/95.
} 


\section{REFERENCIAS BIBLIOGRÁFICAS}

Bidart Campos, G. (1997). El constitucionalismo social. Esbozo del modelo socioeconómico de la constitución reformada en 1994. Economía, constitución y derechos sociales. p.175. Buenos Aires: Ediar.

Cimbali, E. (1900). La funzione sociale dei contratti e la causa giuridica della loro forza obbligatoria. Opere complete di Enrico Cimbali, III, Studi di Diritto Civile. UTET: Turín.

De Lorenzo, F. (2005). Breves reflexiones sobre ficciones y mitos en el Derecho Privado. En Atilio ALTERINI y Noemí NICOLAU (Directores), Carlos A. HERNÁNDEZ (Coordinador), Homenaje al Profesor Miguel Ángel Ciuro Caldani, p. 59 y ss. Editorial La Ley: Buenos Aires.

Duguit, L. (1912). Les transformations genérales du Droit Privé. París: Librairie Felix Alcan.

Esborraz, D. (2014). Los contratos celebrados por adhesión a cláusulas generales predispuestas en el Proyecto de Código civil y comercial (algunas reflexiones comparativas con el derecho italiano)". Revista Responsabilidad Civil y Seguros, (7), p.15 y ss. Buenos Aires: La Ley.

Gil Domínguez, A. (1997). La Constitución socioeconómica de 1994. Economía, constitución y derechos sociales, p.241. Buenos Aires: Ediar.

Hernández, C. (2007). El desequilibrio en los contratos paritarios, predispuestos y de consumo. Revista de Derecho Privado y Comunitario, Nro. 2007-1, p.233.

Santa Fe: Rubinzal Culzoni.

Hernández, C. (2016). El consentimiento contractual. Contratos en el Código Civil y Comercial de la Nación, dirigido por Noemí L. Nicolau y Carlos A. Hernández y coordinado por Sandra A. Frustagli, p.128. Buenos Aires: La Ley.

Josserand, L. (1947). La protección de los débiles por el derecho. Revista de Derecho, Jurisprudencia y administración, T. 45, p.313 y ss.

Lorenzetti, R. (1995). Las normas fundamentales de Derecho Privado. Santa Fe: Rubinzal 
Culzoni.

Nicolau, N. (2016). El contrato en el contexto de la teoría general del derecho. Contratos en el Código Civil y Comercial de la Nación, dirigido por Noemí L. Nicolau y Carlos A. Hernández y coordinado por Sandra A. Frustagli, p.28. Buenos Aires: La Ley.

Nicolau, N. (1995). La constitución nacional y los códigos de derecho privado. Trabajos del Centro, Centro de Investigaciones de Derecho Civil de la Facultad de Derecho de la Universidad Nacional de Rosario, $\mathrm{n}^{\mathrm{o}}$ 1, p. 33 y ss. Rosario: Argentina.

Panunzio, S. (1907). Il socialismo Giuridico (esposizione-critica). Genova: Libreria Moderna.

Rivera, J, (1994). El derecho privado constitucional. Revista de Derecho Privado y Comunitario, Nro. 7, p.27 y ss. Rubinzal Culzoni: Santa Fe.

Rosatti, H. (2016). El Código Civil y Comercial desde el Derecho Constitucional. Santa Fe: Rubinzal Culzoni.

Saba, R. (2011). Constituciones y Códigos: un matrimonio difícil, en http://www. pensamientopenal.com.ar/system/files/2011/12/doctrina32842.pdf

Santarelli, F. (2015). El contrato de consumo en el Código Civil y Comercial de la Nación. Suplemento Especial Nuevo Código Civil y Comercial de la Nación. Buenos Aires: La Ley.

Santarelli, F. (2018). Contrato y mercado. Buenos Aires: La Ley.

Sozzo, C. (2007). Pasado, presente y futuro del principio de orden público referido a los bienes colectivos. Revista de Derecho Privado y Comunitario, $\mathrm{N}^{\circ} 3$, p.349.

Santa Fe: Rubinzal Culzoni.

Stiglitz, G. (2015). La constitucionalización del Derecho del Consumidor. La experiencia argentina. Tratado de Derecho del Consumidor, Tomo I, dirigido por Gabriel Stiglitz y Carlos Hernández, p.225 y ss. Buenos Aires: La Ley. 


\section{CURRICULUM VITAE}

\section{Julieta Belén Trivisonno}

Magíster en Sistema Jurídico Romanístico, Unificación del Derecho y Derecho de la Integración de la Università degli Studi di Roma "Tor Vergata”. Profesora Adjunta de Derecho de los Contratos, Derecho del Consumidor y Práctica Profesional I en la Facultad de Derecho de la Universidad Nacional de Rosario. Docente - Investigadora Categoría V del Programa de Incentivos de la Secretaría de Políticas Universitarias. Integrante integrante y Secretaria del Centro de Investigaciones de Derecho Civil de la Universidad Nacional de Rosario.

jtrivisonno@gmail.com 